\title{
Determinants of Investment Decisions: A Study of Individual Investors on the Zimbabwe Stock Exchange
}

\author{
Peter Hunguru ${ }^{1}$, Vusumuzi Sibanda ${ }^{2}, \&$ Ruramayi Tadu ${ }^{3}$ \\ ${ }^{1}$ Graduate School of Business National University of Science and Technology, P.O. Box AC 939, Ascot, Bulawayo, \\ Zimbabwe \\ ${ }^{2}$ Department of Business Management BA ISAGO University P. Bag BR 94 Gaborone, Botswana \\ ${ }^{3}$ BA ISAGO University P. Bag BR 94 Gaborone, Botswana \\ Correspondence: Vusumuzi Sibanda, Department of Business Management BA ISAGO University P.O. BR 94 \\ Gaborone, Botswana.
}

Received: July 7, 2020

doi:10.11114/aef.v7i5.4927
Accepted: September 7, $2020 \quad$ Available online: September 9, 2020

URL: https://doi.org/10.11114/aef.v7i5.4927

\begin{abstract}
This study investigated factors that inform individual investors in their decision-making on the Zimbabwe Stock Exchange. The main objective was to identify and assess the effect of the behavioural factors on investment decisions of individual investors. A quantitative survey of 291 randomly selected individual Zimbabwe Stock Exchange investors was conducted. Multiple regression analysis was used to calculate the correlation coefficient of behavioural factors and investment decision while correlation analysis was used to measure the strength of the relationship between the independent variables. The findings of the study established that the predictor variables had a strong positive association between them and individual investor decision at a significant level of 0.01 and 0.005 . The findings of the study revealed that individual investor decisions are influenced by the behavioural factors which are; anchoring, availability, gambler's fallacy, overconfidence, herding, loss aversion, mental accounting, regret aversion and representativeness. The study recommends the need for improved information on the stock markets dynamics as well as training on investor awareness programmes to support the decision-making abilities of the individual investors on the ZSE to fully play its rightful role in the development of the economy.
\end{abstract}

Keywords: behavioural finance, investment decisions, psychological factors, rationality

\section{Introduction and Background}

Investment is profitable if one makes the right investment decisions at the appropriate time and invests in the right investment options. It is difficult for an investor to have a full set of information on the risks and returns available in the stock market to be able to be successful as there are various factors influencing hence rendering the process of making the right investment decision difficult. Consequently, individual investors are affected differently by these factors. Investors are therefore forced to gather as much information as ppossible so as to minimise the risk inherent in uninformed investment decisions. Globalisation and technological advancements have made access to capital markets quicker and easier for the ordinary people. Empirical evidence indicates that investors are rational and always want to make well informed decisions that maximise their returns. Proponents of this argument believe that markets operate efficiently characterised by a large number of rational wealth maximisers each trying to get the best returns in a perfectly competitive market. The leading traditional financial theories supporting this view include the Modern Portfolio Theory (MPT), the Capital Asset Pricing Model (CAPM) and the Efficient Market Hypothesis (EMH). In an efficient market, market forces lead to equilibrium and prices of individual securities will reflect all the information and knowledge of past, present and any expected future events. However, recent studies by Kengatharan and Kengatharan (2014), Tripathy (2014) and Wamae (2013) show that investor behaviour is not always rational; in fact, sometimes it is systematically irrational. This irrationality in turn makes markets unpredictable and further complicates the investment making decision process for the individual investor. These stock market instabilities increase the risk related to investment. Behavioural finance explains why investors make systematic errors in a bid to get the best returns from the market. Behavioural finance explores the capital markets and gives insight on what causes market anomalies, speculative tendencies and in extreme scenarios market crashes. 
As an emerging branch, behavioural finance seeks to identify and explore psychological factors that influence individual investment decisions. The theories attempt to test the psychology, emotions, and cognitive influence on investor behaviour. Many behavioural finance factors such as anchoring, over-confidence, gambler's fallacy, loss aversion, mental accounting, representativeness, self-control, availability, demographic factors, and regret aversion, among others, influence investors' decisions in the stock markets. Levine (1997) argues that investment is the primary push for economic growth and development of a country. Levine further postulates that the growing body of empirical analyses, at firm, industry and country level demonstrate a strong positive link between functioning of the financial system and long run economic growth. Thus, a strong link between a country's stock market and economic activity exists. On the other hand, Ahmad, Ibrahim and Tuyon (2017) posit that investors' behaviour determine the price of stock and market behaviour. Hence it is important to understand the behaviour of the investor. The capital market players in Zimbabwe cannot ignore these behaviours as individual investors are a key component in the development of the country. Furthermore, to achieve the middle-income targets and sustainable development goals, the Government of Zimbabwe has embarked on several initiatives aimed at financial inclusion for the individual investor.

The purpose of this study was to explore the behavioural factors affecting individual investment decisions on the Zimbabwe Stock Exchange (ZSE). The study adopted a deductive approach, using structured questionnaires which were administered to a sample of 291 individual investors on the ZSE. The responses provided insight to the theory or phenomenon as to what behavioural factors determine individual investment decisions on the ZSE.

The study of behavioural finance allows cognitive psychology to play an important role in investment choice. While traditional theories point to rational behaviour on the part of investors, empirical evidence points to the contrary. People's financial decision making may be somewhat affected by behavioural biases. As people have beliefs or preferences that do not meet the traditional fundamentals of rational decision making, this makes it imperative to analyse the effects of these behavioural biases, especially if their cognitive errors impact prices and the efficient operation of stock markets.

\subsection{Capital Markets of Zimbabwe}

The following section provides the major players and components of the capital market.

\subsubsection{Securities and Exchange Commission of Zimbabwe (SECZ)}

The Securities and Exchange Commission of Zimbabwe (SECZ)'s role in addition to monitoring and regulating capital market participants include; regulating trading and dealing in securities, registration, supervision, licensing and regulating securities exchanges. The commission promotes free, fair and orderly trading in the capital and securities markets in Zimbabwe and also advises the Government of Zimbabwe on all matters relating to securities, capital markets and investor education campaigns to promote awareness to the ordinary people.

\subsubsection{Zimbabwe Stock Exchange (ZSE)}

The Zimbabwe Stock Exchange (ZSE)'s history dates back to 1896 but only opened to foreign investment in 1993. In 2019 the Exchange had fourteen registered brokerage firms, and 64 active counters. There are four indices on the ZSE, the Zimbabwe Industrial Index, the Zimbabwe Mining Index, the Top Ten Index and the All Share Index. The ZSE has evolved over time to be one of the longest established capital raising platforms in Africa. Trading is online via the Automated Trading System (ATS) and settlement period is T+3 business days. Since July 2015, the ZSE got automated and migrated away from the traditional open-outcry manual based trading system.

\subsubsection{Central Securities Depository (CSD)}

A CSD is a company that operates an electronic book entry system to record and maintain securities and to register their transfer. Securities are maintained in electronic form in the investor's account just like how money is kept in the form of electronic credits in any bank account (Chengetedzai, 2019). In a CSD system, ownership will be changed as soon as securities move from one investor account to another. The CSD system can be depicted as a clearing and settlement platform which facilitates after-trade activities of the stock market. The CSD of Zimbabwe is operated by Chengetedzai Depository Company Limited which was incorporated with a mandate to establish and operate a central securities depository for the Zimbabwe securities industry (Chengetedzai, 2019).

\subsection{Capital Market Development Initiatives in Zimbabwe}

The Zimbabwe Stock Exchange (ZSE) has had a history of good performance on the African continent and outperformed most African Stock Markets for the period 1996 to 2008. During the same period, capital market players led by the regulator, Securities and Exchange Commission of Zimbabwe have initiated intensive capital market developments which have led to improved market efficiency, liquidity and transparency. The government of Zimbabwe also launched Financial Inclusion Goals 2020 and achievement of middle-income economy by 2030 and the Transitional Stabilisation Programme (2018-2020). These national initiatives can only succeed with encouragement for broader participation by all interested players on the capital markets. 
In 2018 an investor awareness campaign was launched by the Securities and Exchange Commission of Zimbabwe (SECZ) targeting the individual investor. The campaign aimed at making investors aware of the investment opportunities available on the Zimbabwe Capital Market Landscape. The Central Securities Depository (CSD) has also made endeavours and partnered stockbrokers to offer a cheaper custodial service to individual investors who ordinarily find the fees charged by conventional custodian banks prohibitive. This broker-controlled custodial model has seen a huge increase in individual investor account opening. However, actual investment by the individual investors remains low. The Securities and Exchange Commission of Zimbabwe (SECZ) in partnership with Escrow Systems launched an online mobile trading platform, C-Trade which allows for investors to place trades from their mobile devices from any location as long as they have installed the application and have data connectivity. As indicated by Escrow Systems (2019), the minimum requirement to trade has also drastically dropped to only US $\$ 10$ thus making trading affordable to individual investors.

Trading of shares that are listed on the ZSE was automated in 2015 whilst the clearing and settlement of trades was automated earlier in 2014. This has allowed for more companies and new products to come onto the stock market. These strategies have made the Zimbabwe capital market efficient and competitive in the region. Due to these technological advances, overall trading costs for buying and selling have reduced from $4.188 \%$ to $4.136 \%$ as indicated by the Securities (Registration, Licensing and Corporate Governance) Rules 2014. The Securities and Exchange Commission of Zimbabwe (SECZ) continues to review rules and legislation around the investor protection fund (IPF or "Fund") whose purpose is to provide compensation to investors for undue losses arising from collapse of a market player licensed by SECZ being insolvent due to malpractice or other such realted causes (SECZ, 2019).

Advances in capital markets and accessibility to the ordinary person have seen a gradual increase in individual enrolment and participation on the stock market as indicated in Table 1.

Table 1. Individual investors on the CSD

\begin{tabular}{lccccc}
\hline Year & $\mathbf{2 0 1 4}$ & $\mathbf{2 0 1 5}$ & $\mathbf{2 0 1 6}$ & $\mathbf{2 0 1 7}$ & $\mathbf{2 0 1 8}$ \\
\hline Individual Investors & 506 & 1,815 & 2,471 & 4,960 & 6,702 \\
\hline
\end{tabular}

Source: CSD Operating Update - 31 December 2018, p.1

There is a wide array of factors that influence the way investment decisions are made. Many studies have been conducted in other jurisdictions which do not resemble the same level of development as Zimbabwe. Despite success stories on investment by individuals on the stock market in other countries, no study has specifically focused on this sector in Zimbabwe, and if any, the studies have not focused on the behavioural factors which form the subject matter of this study. In Zimbabwe, this was the first attempt at identifying and studying the behavioural factors that determine investment decisions. It is evident that there exists a knowledge gap that needs to be closed by pursuing a rigorous research. The knowledge gap exists as to what behavioural factors affect the buying and selling decisions of individual investors on the ZSE. It is against this background that the researcher undertook to investigate the behavioural factors that affect individual investment decisions on the ZSE. The main objective of the study was to identify and assess the impact of the behavioural factors on investment decisions of individual investors.

\section{Conceptual Framework}

Figure 1 depicts the relationship between the 10 independent variables which include anchoring bias, availability bias, gambler's fallacy bias, herding bias, loss aversion bias, mental accounting bias, over-confidence, regret aversion and representativeness bias and the dependent variable, which is the investment decision among the individual investors.

The underlying assumptions of traditional finance theories form the basis on which behavioural finance has been built as they refute some of the traditional theories' key assumptions. A review of the behavioural finance theories was conducted leading to a discussion of the factors which affect individual investor decision-making. 


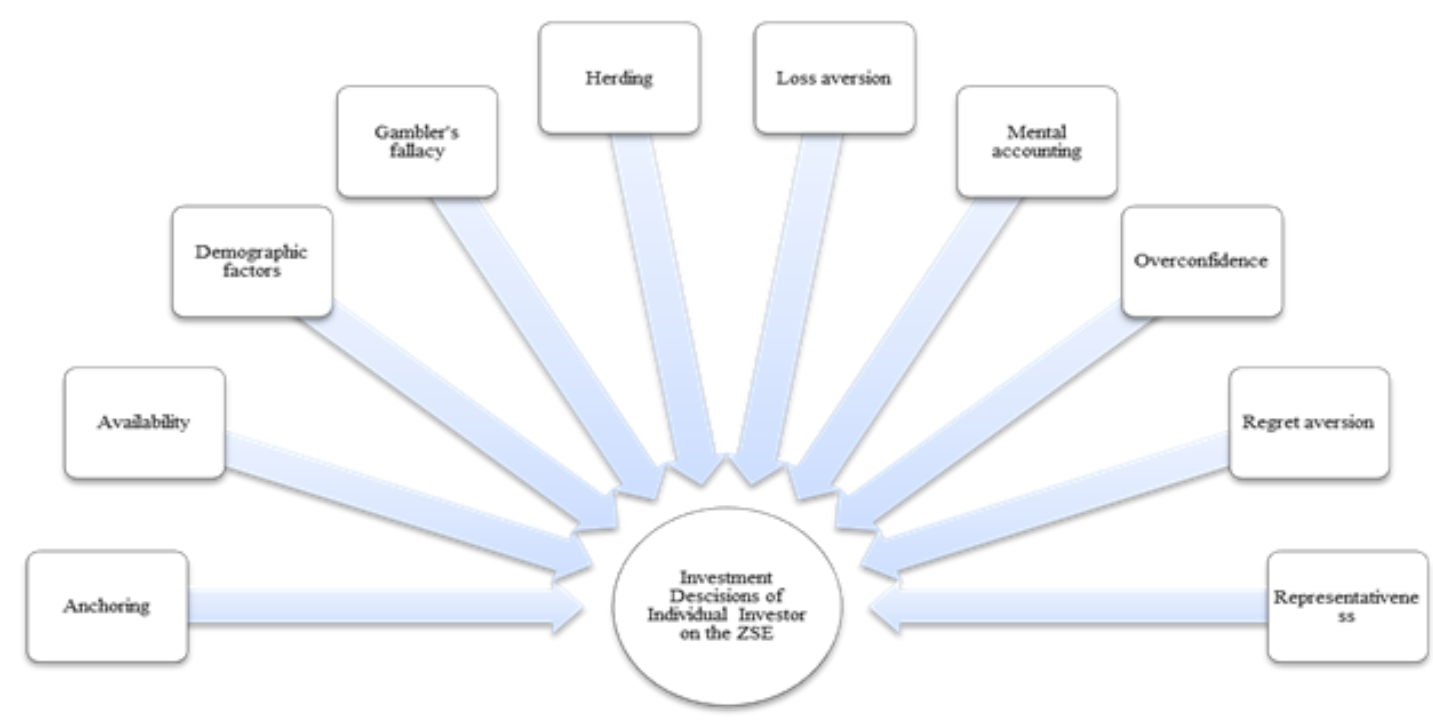

Figure 错误!文档中没有指定样式的文字。. Conceptual framework

\subsection{Behavioural Finance Theories}

Behavioural finance has emerged as a result of the shortcomings of traditional finance theories. Behavioural finance relaxes the assumption of efficient market hypothesis in its explanation of the financial market phenomenon and argues not all investors are rational hence the need to appreciate that certain human biases influence investor decisions (Chang, 2008). As observed by Shiller (2002), behavioural finance emphasises the need to appreciate the human psychological biases that are related to the financial markets. Furthermore, Sewell (2011) postulates that behavioural finance refers to how investors are psychological viewed as well as the impact they have on the stock market. On the other hand, Agarwal and Panwar (2014) postulate that behavioural finance unearthes factors responsible for capital markets failure.

\subsubsection{Prospect theory}

The prospect theory developed by Kahneman and Tversky (1979) contends that people would rather settle for moderate gains than gun for exceptional returns with high risk exposure. According to the prospect theory, a tendency to go the opposite when faced with obvious targets is common. Ricciardi (2004) lends support to the assertion and further assumes that people show tendency of loss aversion.

\subsubsection{Cognitive Bias Theory}

Cognitive bias theory suggests individuals may make some errors in their decision making based on their line of reasoning, mind or beliefs. Beck, Rector, Stolar and Grant (2008) propose that self-perception regulates both behaviour and emotions. How people think, identify, remember and acquire knowledge draws from cognitive psychology. The import of cognitive bias is that an individual must be conscious of the environment in which they make the decision so as to avoid biases which may be detrimental. Therefore, this study explores factors that influence investors' decision-making.

\subsection{Factors Influencing Investment Decisions}

A successful investment depends on the combination of identification of psychological biases and the knowledge to reduce or address the biases (Jureviciene and Kristina, 2012). How an individual makes an investment decision is quite complicated as many factors come into the fray triggering different moves resulting in varied outcomes. Different characteristics account for investor differences and these include demographic factors, socioeconomic background, educational level, sex, age and race amongst other factors. Consequently, heterogeneous decisions are common phenomena as these factors impact investors differently. Due to the inevitable complexity in investment decision making, scholars have continued to explore the central factors in the process and this study is no exception. The psychological factors that impact on investor decision-making, which also form factors to be investigated in this study are discussed below. 


\subsubsection{Anchoring Bias}

Anchoring was introduced by Amos Tversky and Daniel Kahneman. Anchoring relates to the process of generating estimates of how likely uncertain occurrences are by viewing a primary value or initial position and varying it until it fits an ultimate decision (Kudryavtsev and Cohen, 2011). Investors normally make decisions and take positions influenced by pre-exisiting data or information than the subsequent one and this has a tendency to skew their decisions. The pre-existing data, as explained by Agarwal and Panwar (2014), can be established by coming up with a pseudo problem or incomplete calculation. In the stock markets, this concept sheds light on why investors put much emphasis on the initial purchase price when selling or analysing stocks (Luong and Thu Ha, 2011). This also explains why some investors have a tendency to cling onto stock of certain counters even when negative returns are evident.

\subsubsection{Availability Bias}

Murgea (2010) defines availability bias as a judgmental heuristic and related to the realisation frequency of decisions. Laibson and Zeckhauser (1998) further elaborate that individuals thus, attribute the realisation frequency of a decision to the number of times of occurrence of a similar decision or availability of example cases. It allows people to forecast the likelihood of such a scenario to repeat itself. Investors depend on readily available information to give impetus to their decisions thus less weight is given to information that points to events that rarely occur. In most instances stock that is more publicised than other stocks attract more investors regardless of its size of return or profitability. However, coincidentally in many instances these high attention stocks do not outperform the market.

\subsubsection{Gambler's Fallacy Bias}

Gambler's fallacy is defined as a psychological influence in which people think that the likelihood of an outcome has changed, when in reality it has not changed at all (Barron and Leider, 2010). It is the mistaken belief which people develop for unrelated events which a linkage is assumed. A classic example is when playing a lottery, where one never repeats the previous numbers betted on in the previous round of the lottery (Rakesh, 2014). In the study of the investors on the Bombay Stock Exchange, Rakesh (2014) found that there existed evidence of gambler's fallacy in expectations of investors thereby affecting the quality of decisions adversely. Several studies have shown that gambler's fallacy is a prominent factor influencing investment decisions by individual investors. Gambler's fallacy is premised on the belief that opposite transactions would eventually force each other into equilibrium as advanced by Barron and Leider (2010) and that any misalignments will eventually self-correct (Subash, 2012). This is viewed by Kahneman, Knetsch and Thaler (1991) as the wrong belief in the rules of justice and luck. The belief is that the longer the run of an observation, the sooner that the pattern will eventually shift and the opposite becomes true. Sudhir (2012) observed that as soon as the investor incorrectly anticipates a position in the market; the personal bias takes over, leading to poor judgments based on this self-belief. Based on the assumption, which is false, that prices are about to drop, because they have been on an upward trend for long, investors will sell only for the upward trend to maintain further into the horizon. This psychological factor often leads individual investors to enter or exit a stock too early without reaping the full profits of the stocks.

\subsubsection{Herding Bias}

Herd behaviour relates to a situation where people start acting like others instead of taking their own independent decisions which take cognisance of risk and return (Lin, 2011). In other words, herding bias is when investors join the bandwagon and blindly follow what famous investors are doing as the basis of their decisions. Individual investors tend to exhibit this behaviour more than other types of investors. Herd is a cognitive bias. It draws its popularity due to the fact that people seek refuge in numbers and tend to follow the behaviour of the majority to feel safe. These observations are replicated in the financial sector particularly the stock markets where many investors will tend to follow stocks that have a huge following from the majority of the investors. As the demand for the stock increases due to the herd behaviour, the stock price increases by more than its true level resulting in overpricing of the stock. This is the basic reason of the creation of bubbles in the stock markets, if continued for a longer period. Thus, Lakshmi, Visalakshmi, Thamaraiselvan, and Senthilarasu (2013) asserted that herd behaviour effect depends on investors' time horizon and investment characteristics. The herd behaviour exhibited by investors is in contrast to the rationality principles promulgated by the traditional finance theorists. Lin (2012) sheds more light on the characteristics and personalities of the investors who are prone to herd behaviour when he points out that these investors generally have low-self-confidence. As a great concern to market stability, Shiller (2015) argues that herding in stock markets can cause overreactions and destabilise operations of the stock market.

\subsubsection{Loss Aversion Bias}

The loss aversion theory has its roots from the prospect theory which was developed by Kahneman and Tversky in 1979. Different scholars have conducted studies on the effect of loss aversion on decision making under different situations. Loss aversion is a form of regret aversion. Also investors are more likely to avoid the investment choices in which the 
probability of loss is higher in so doing; investors will simultaneously avoid the feeling of regret of losing their money. Thus loss aversion is the tendency by investors to fear and avoid losses to the detriment of profits which consequently prevents investors from exiting from a lossmaking stock.

\subsubsection{Mental Accounting Bias}

Mental accounting bias was first explored by Professor Richard Thaler in 1980. Richard Thaler developed the theory to describe the way in which a person intuitively processes a transaction in their mind and quantifies the utility they expect to generate and or receive. According to this theory, people will usually classify their wealth into current income, current assets and future incomes. Thus, investors will typically spend more from current income and treat future income conservatively because of the mental accounting bias. Tversky (1995) explains that mental accounting is the behaviour that exhibits itself in the human mind to visualise their finance into separate mental accounts and thereby these divisions reflect themselves in the people's behaviour towards each separate mental account (Thaler, 2001). However, due to this separation of mental accounts and the mind-set created in the investor, wrong decisions may ensue. In mental accounting, investors place different weights on the value of money due to its source. Thus, money earned from interest and lottery money will be treated differently and placed in different mental accounts when it should be combined to maximise profitability (Ritter, 2003). Pompian (2012) notes that mental accounting may lead to investors holding onto investments that have proven to be successful. However, overall mental accounting is not destructive to investors since it helps in instilling future behaviour in decision making as it allows for review of previous decisions.

\subsubsection{Overconfidence Bias}

Kahneman and Tversky (1979) define overconfidence as a situation when an individual considers their skill, knowledge and ability to be greater than the actual performance. This is one of the most common psychological biases and is one of the main building blocks in the field of behavioural finance. A study by Inaishi, Toya, Zhai, and Kita (2010) established that overconfidence gets deeply entrenched the more investors' decisions proved true. Subash (2012) highlights the overconfidence aspect in investors when it comes to picking stocks especially when faced with enter or exit decisions. The findings of the study carried out by Jamshidinavid, Chavoshani, and Amiri (2012) concluded that outgoing and sociable investors exhibited overconfidence bias.

\subsubsection{Regret Aversion Bias}

Regret aversion bias causes people to avoid taking decisions because they think that the decisions they take may not be the optimal decisions. The people who suffer from regret aversion bias are reluctant to participate in stock markets. In some instances, regret aversion bias will hinder the investor from taking advantage of great opportunities that present themselves. The behaviour shown by these investors also range from completely avoiding stock markets experiencing a bearish phase, staying invested or holding onto the "value-stock" and not to reap the profits available by selling, in fact they want to avoid the regret of further price increase after selling the stock. Sudhir (2012) points out that this feeling is not confined to regret at financial loss but include the blame for the decision that led to the loss itself. Pompian (2012) posits that regret-averse investors will strive to avoid the pain that is associated with badly judged actions. This affects participation by investors on the stock market as investors steer clear of having to make decisions due to a pre instinct belief that their decisions may be wrong. Pompian (2012), further postulates that due to this overcautiousness, investors cling onto losing positions for an extended time thereby compounding their losses when an early exit would have abated them. In pursuit of avoiding the prospect of making a mistake, investors will tend to flock to stock which is deemed dependable and trustworthy regardless of its true underlying value thereby stimulating herding behaviour as discussed in 2.4.3 (Sudhir, 2012).

\subsubsection{Representativeness Bias}

Representative bias, as defined by Kahneman and Tversky (1974), is the inclination people have to perceive outcomes as per their own pre-existing ideas or perception. Thus, the way of processing new information follows a consideration of past events as part of the thought process. People tend to believe that if two objects are similar, then they are likely to have a correlation with each other which unfortunately is not always the case. It affirms that when people evaluate the prospect of uncertain events, they are inclined to predict its outcome by seeking the closest match to past patterns (Kahneman and Tversky, 1974). Goldstein (2013) further highlights that representativeness bias involves a process where individuals make evaluations based on the similarity of a case with another previous case. Singh (2012) argues that psychological factors sometimes lead to biases, particularly when things change leading to inferior investment decisions.

\subsubsection{Demographic Factors}

Demographic factors such as age, gender, knowledge of capital markets, level of education, income level, occupation and marital status amongst other demographic factors greatly influence investment decision-making. Kaleem, Wajid and 
Hussain (2009) in a study conducted in Rajasthan concluded that age, income, language and education have a significant role in shaping the investment style of an investor. Another study, conducted by Kartasova (2013) identified the factors developing irrational individual investors' behaviour by evaluating data from Lithuanian stock market and showed that there was a relationship between investment decision and individual investors' age, gender, investment experience and occupation. The results also showed that overconfidence, anchoring, mental accounting and herd behaviour made the strongest influence on the financial decision-making process. More studies have also shown that psychological biases are influenced by demographics (Gunay and Demirel, 2011; Jain and Mandot, 2012). In a study conducted by Faff, Hallahan and McKenzie (2009), evidence showed that the higher the age of the individuals, the lower the risk tolerance. A study of 300 investors conducted by Jain and Mandot (2012) examined how these demographic factors impacted on investors in Rajasthan. Results showed that age, sex, marital status, income, knowledge of the market and qualifications all greatly influenced the decision-making process. Gunay and Demirel (2011) also found similar outcomes which highlighted the fact that a person's gender was related directly to behavioural influences. Thus, Gunay and Demirel (2011) resolved that an investor's gender and their level of savings are dominant demographic factors with strong positive links to financial behavioural factors.

Based upon the factors discussed above, a theoretical framework was formulated as presented in Figure 2.

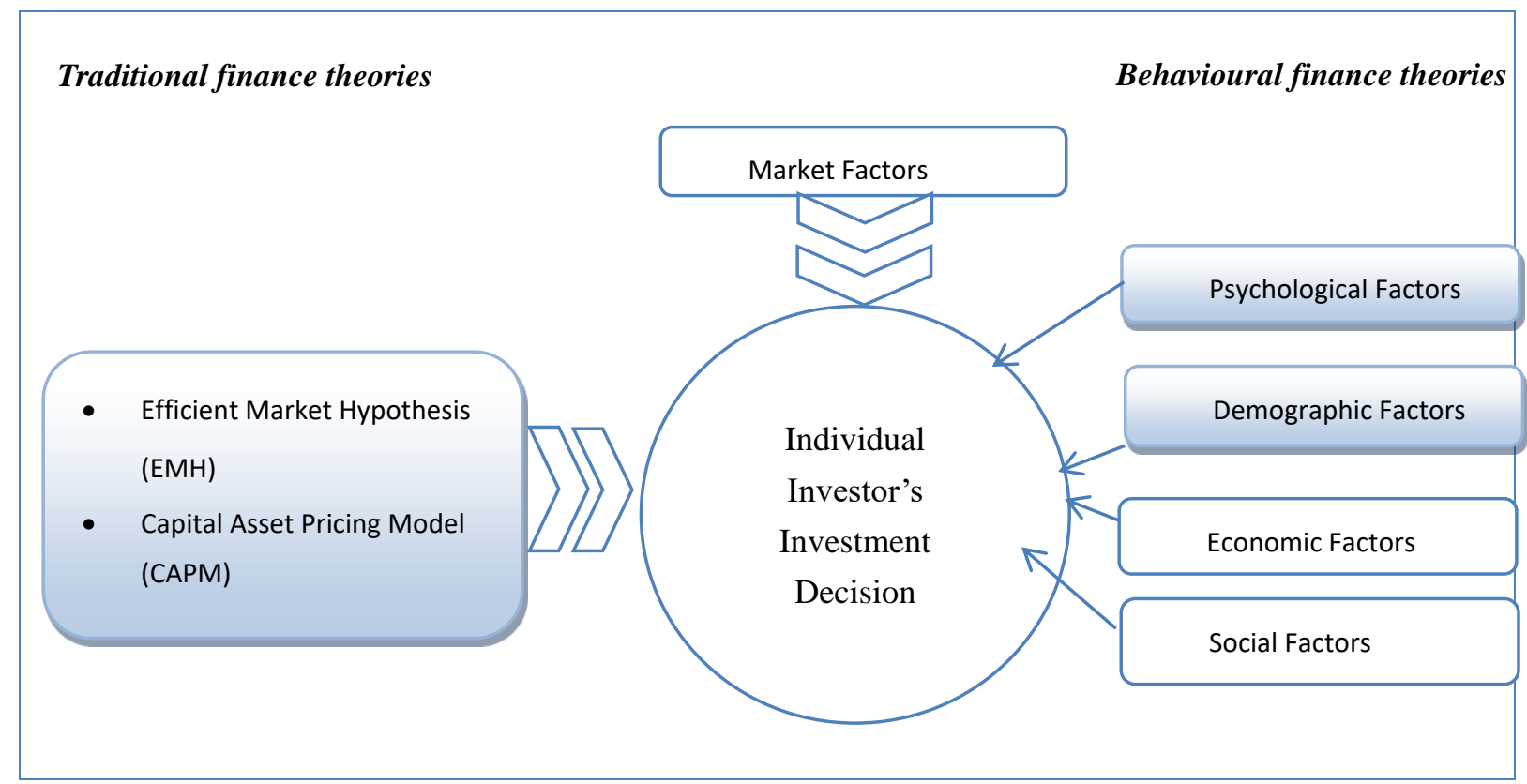

Figure 2. Theoretical framework

Thus, according to the literature that explains investors' behaviour presented in 2.2, a large number of factors have been identified. The studies also show that the effects of all behavioural biases are not the same for all types of investors. They are market specific and dependent upon the demographic profile of the investors as well.

\section{Methodology}

This quantitative study was conducted in Harare, the capital city of Zimbabwe. The population for this research was the individual investors on the Zimbabwe Stock Exchange. There were 6702 individual investors at the ZSE as at 31 December, 2018. Probability sampling was used for selecting respondents. Simple random sampling was then used to select the sample at random from the sampling frame using random number tables. The study used Randomizer.org (2019) to generate random numbers which were used to select the respondents in which a sample of 291 investors was estimated and drawn for the study.

A five-point Likert scale questionnaire was used as the primary data collection tool. The questionnaire was further divided into two sections, the first related to the demographic features of the respondents, and second related to the psychological factors affecting their investment decisions. Alpha Cronbach tests were run on the questionnaire items per each indicator to confirm the reliability of the research instruments and all the variables fell within the acceptable range. The questionnaires were administered to 291 respondents selected using random sampling technique from the list of active investors from the Central Securities Depository. A total of 201 respondents filled in and returned the questionnaire yielding a response rate of $69.07 \%$. This response rate was good and representative and conforms to 
Mugenda and Mugenda (2003) stipulation that a response rate of 50\% is adequate for analysis and reporting whereas a response rate of $60 \%$ and above is good.

Multiple regressions were used for many-to-one relationships. The links between two variable sets used in investigating a many-to-many relationship can be explored by means of the canonical correlation multivariate approach. Individual investment decision making on the Zimbabwe Stock Exchange was the dependent variable. The behavioural factors affecting individual investment decisions were identified as independent variables. The following multiple regression model was adopted in the study.

$$
\begin{gathered}
\mathrm{Y}=\beta 0+\beta 1 \mathrm{X} 1+\beta 2 \mathrm{X} 2+\beta 3 \mathrm{X} 3+\beta 4 \mathrm{X} 4+\beta 5 \mathrm{X} 5+\beta 6 \mathrm{X} 6+\beta 7 \mathrm{X} 7+\beta 8 \mathrm{X} 8 \\
\text { Where: } \mathrm{Y}=\text { Individual investment decision }
\end{gathered}
$$

$\{\beta 1 ; \beta 2 ; \beta 3 ; \beta 4 ; \beta 5 ; \beta 6 ; \beta 7$ and $\beta 8\}=$ The coefficients for the various independent biases.

$\mathrm{X} 1=$ Anchoring

$\mathrm{X} 2=$ Availability

X3 = Gambler's fallacy and Overconfidence

$\mathrm{X} 4=$ Herding

$\mathrm{X} 5=$ Loss aversion

X6 $=$ Mental accounting

$\mathrm{X} 7=$ Regret aversion

$\mathrm{X} 8=$ Representativeness

In the model $\beta 0$ is the constant term while the coefficient $\beta 1$ to $\beta 8$ are sensitivity of the dependent variable (Y) to unit change in the independent variables (X1, X2, X3, X4, X5, X6, X7 and X8). The dependent variable was measured by asking respondents to assign a weight on the impact of each behavioural factor to their investment decision.

\section{Findings and Discussion}

\subsection{Average Investment}

The respondents were asked to indicate the amount invested on the Zimbabwe Stock Exchange for 2018 in Zimbabwe currency (RTGS\$). The majority of investors (50.25\%), had average investment for 2018 on the ZSE ranging between RTGS\$1,001 and 5,000, 14.92\% had average investment for 2018 of more than RTGS\$ 50,000, 14.43\% had average investment for 2018 on the ZSE ranging between RTGS\$ 5,001 and 10,000 with 10.45\% of the investors with an average investment for 2018 on the ZSE below RTGS\$ 1,000 whilst the remaining 9.95\%'s investment outlay for 2018 was between RTGS\$10,001 and 50,000.

\subsection{Trading Experience on the ZSE}

The experience one has attained on the Zimbabwe Stock Exchange demonstrates the extent of knowledge they have around the issues sought in this study. This study is about the behavioural factors influencing investment decision in stock market where the focus was on the individual investors on the Zimbabwe Stock Exchange. The study, therefore, sought to establish the length of time that the respondents had been trading on the Zimbabwe Stock Exchange. The study revealed that $62.7 \%$ of the respondents had been participating on the Zimbabwe Stock Exchange for the past 1 to 3 years, while $22.4 \%$ of them had been participating for over 5 years, with $8.5 \%$ of the respondents having experience of between 4 and 5 years, while the last $7.5 \%$ had less than 1 year experience.

Table 2. Trading experience on the ZSE

\begin{tabular}{lll}
\hline Experience & Frequency & Percent \\
\hline Less than 1 year & 13 & 6.5 \\
1 -3 years & 126 & 62.7 \\
4-5 years & 17 & 8.5 \\
More than 5 years & 45 & 22.4 \\
Total & 201 & 100 \\
\hline
\end{tabular}

Source: Research Output

\subsection{Behavioural Factors}

This study sought to identify and assess the impact of the behavioural factors on investment decisions of individual investors on the Zimbabwe Stock Exchange. To achieve this objective the study requested the respondents to rate statements related to the eight behavioural biases using a five-point Likert scale. 
The influence of behavioural variables on the investment decisions are identified by calculating the values of the sample mean of each variable. The variables which meet the requirements of the indicated factor analysis are picked to demonstrate their scores. With the use of a five-point Likert scale to measure the influence of the factor variables, the mean values of these variables can determine their influence on the investment decision making based on the following criteria:

\subsubsection{Effect of Anchoring Bias on Investment Decisions}

Table 3. Effect of anchoring bias

\begin{tabular}{lcc}
\hline Variables & Mean & Std. Deviation \\
\hline Q12: Based on the current price of a security, I can predict its future price. & 3.88 & .690 \\
Q13: I usually use the purchase price as a benchmark for a sell decision. & 3.92 & .720 \\
Q14: If a stock hits its year high, I will sell the stock immediately. & 3.80 & .735 \\
\hline
\end{tabular}

Source: Research Output

In terms of anchoring investors confirmed forecasting future price of a stock based on its current price $($ mean $=3.88)$, whereas for selling decisions investors on the Zimbabwe Stock Exchange exhibited tendencies of using the purchase price of a stock as a benchmark for sell decisions with a mean of 3.92. The investors would sell the stock immediately when its price hits the year high with a mean of 3.80. This accentuates the moderate effect of anchoring bias on individual investor decision making on the Zimbabwe Stock Exchange.

\subsubsection{Effect of Availability Bias on Investment Decisions}

Table 4. Effect of availability bias

\begin{tabular}{lcc}
\hline Variables & Mean & Std. Deviation \\
\hline Q15: If I want to buy shares in a particular company, I will rely on information & 3.92 & .751 \\
gathered from colleagues. & 3.96 & .655 \\
Q16: If I want to buy shares in a particular company, I will rely on information & \\
gathered from stock market experts. & 3.95 \\
$\begin{array}{l}\text { Q17: I have a preference for local securities than foreign counters because local } \\
\text { securities have readily available information. }\end{array}$ & .590 \\
\hline
\end{tabular}

Source: Research Output

With a mean of 3.96, most investors relied on information from stock market experts to make investment decisions. This confirms the existence of availability bias at the Zimbabwe Stock Exchange. The investors preferred local counters to foreign counters due to the readily available information on the local counters with a mean of 3.95. Investors depend on readily available information to give impetus to their decisions thus less weight is given to information that points to events that rarely occur. In most instances, stock that is more publicised than other stocks attract more investors regardless of its size of return or profitability.

\subsubsection{Effect of Gambler's Fallacy and Overconfidence Biases on Investment Decisions}

Table 5. Effect of gambler's fallacy and overconfidence biases

\begin{tabular}{lcc}
\hline Variables & Mean & Std. Deviation \\
\hline Q18: I can easily predict the end of a bullish or bearish run on the ZSE. & 3.89 & .756 \\
Q19: I am certain that my knowledge of stock markets can help me to outperform the & 3.93 & .574 \\
market. & 3.94 & .766 \\
Q20: I am a very experienced investor & 3.68 & .529 \\
Q21: I feel I can forecast future stock prices better than others. & 3.75 & .781 \\
Q22: I am able to anticipate a good run and a poor run and make optimum & \\
investments.
\end{tabular}

Source: Research Output

As shown in Table 5, investors of the Zimbabwe Stock Exchange affirmed that gambler's fallacy and overconfidence biases had a moderate impact on their decision-making with mean from 3.68 to 3.94. This can be noted by the fluctuations in prices on the ZSE especially when prices sometimes go up regardless of the issuing companies' performance going the opposite direction. This trend occurs when investors fail to judge the market correctly and fail to timely exit or enter the market. 


\subsubsection{Effect of Herding Bias on Investment Decisions}

Table 6. Effect of herding bias

\begin{tabular}{lcc}
\hline Variables & Mean & Std. Deviation \\
\hline Q23: By closely following the market trend, I typically respond quicker to changes of other & 4.05 & .438 \\
investors' decisions and follow the new trend on the market. & 4.10 \\
Q24: I feel majority opinion about profits on the ZSE and investment objectives are often \\
correct.
\end{tabular}

Source: Research Output

The investors strongly agreed that they typically respond quickly to changes of other investors' decisions (mean $=4.05$ ). This shows the high impacts of herding behaviour amongst individual investors on the ZSE on decision-making. This can be attributed to relative lack of investor education leading to investors resorting to following the market or trend.

\subsubsection{Effect of Loss Aversion Bias on Investment Decisions}

Table 7. Effect of loss aversion bias

\begin{tabular}{lcc}
\hline Variables & Mean & Std. Deviation \\
\hline Q27: After encountering a heavy loss on my investments, I become more risk averse. & 4.20 & .541 \\
Q28: I prefer not to invest in stocks with high unpredictability & 4.18 & .646 \\
Q29: I will wait for the market to start performing before increasing my investment. & 4.05 & .598 \\
\hline
\end{tabular}

Source: Research Output

Table 7 shows that most of the investors become more risk averse after encountering a heavy loss on investments $(\mathrm{mean}=$ 4.20). This is a normal reaction of investors because failure usually depresses them. The investors also strongly agreed that stocks with high unpredictability were avoided (mean $=4.18$ ). Most investors would wait for the market to recover or start performing before increasing their investment (mean $=4.05$ ). These observations point to a stock market where investors are more inclined to be loss averse and thereby sceptical to further their investments if encountered with such scenarios. This buttresses the fact that loss aversion has never been an ideal strategy based on the principle of "high riskhigh return".

\subsubsection{Effect of Mental Accounting Bias on Investment Decisions}

Table 2. Effect of mental accounting bias

\begin{tabular}{lcc}
\hline Variables & Mean & Std. Deviation \\
\hline Q30: I am more concerned with the performance of each security individually and not the & 3.86 & .380 \\
portfolio as a whole. & 3.93 & .678 \\
Q31: I treat each item of my investment portfolio separately. & \\
\hline
\end{tabular}

Source: Research Output

Most investors were more concerned with the performance of each security individually than the portfolio as a whole $($ mean $=3.86)$ as shown in Table 8 . The investors also agreed that they treat each item of the investment portfolio separately (mean $=3.93$ ). The result confirms the availability of mental accounting bias in individual investment decision making at the ZSE.

4.3.7 Effect of regret aversion bias on investment decisions

Table 9. Effect of regret aversion bias

\begin{tabular}{lcc}
\hline Variables & Mean & Std. Deviation \\
\hline Q32: I usually quickly sell off shares that have increased in value whilst holding onto & 4.21 & .761 \\
those that have decreased in value. & & \\
Q33: I have a tendency to keep securities that are losing value waiting for better times & 4.18 & .780 \\
Q34: I don't buy stocks that have decreased in value & 4.00 & .686 \\
\hline
\end{tabular}

Source: Research Output

Table 9 shows that regret aversion has a high effect on the investment decisions of investors at the ZSE with means of 4.21, 4.18 and 4.00 respectively. This insinuates that ZSE individual investors seem to be more willing to sell shares increasing in value than decreasing ones (mean $=4.21$ ). However, investors should ideally have investment strategies that may allow for an acceptable range of profit or loss on securities. This is due to the fact that investors tend to cling onto stock and only 
offload them as a last resort usually when a lot of damage had been done. This is confirmed by a mean of 4.18 , with most investors agreeing that they would hold onto losing shares waiting for them to start gaining. Most investors agreed outright that they do not buy stocks that have decreased in value.

4.3.8 Effect of Representative Bias on Investment Decisions

Table 10. Effect of representative bias

Variables

Mean

Std. Deviation

Q35: Good stocks are companies with consistent earnings and growth.

3.95 .630

Q36: I avoid investing in companies with poor performance history

3.56

.517

Source: Research Output

The investors indicated that good stocks were those of companies with consistent earnings and growth (mean $=3.95)$, whereas they would avoid investing in companies with poor performance history (mean $=3.56$ ) as shown in Table 10 . This infers presence of representative bias in investor decision making on the ZSE. The descriptive statistics show that the independent variables are significant in investment decision since all of them had their mean above 3.00 implying that most of the investors deemed them relevant in decision making.

\subsection{Inferential Statistics}

Correlation analysis was used to measure the strength of the relationship between the independent variables, that is, the relationship between individual investor decision, anchoring bias, availability bias, gambler's fallacy and overconfidence biases, herding bias, loss aversion bias, mental accounting bias, regret aversion bias and representativeness bias. Regression analysis established the relative significance of each of the variables on investor choices.

\subsubsection{Regression Analysis}

Table 11. Model summary

\begin{tabular}{|c|c|c|c|c|c|c|c|c|c|}
\hline \multirow[b]{2}{*}{ Model } & \multirow[b]{2}{*}{$\mathrm{R}$} & \multirow[b]{2}{*}{ R Square } & \multirow[b]{2}{*}{$\begin{array}{l}\text { Adjusted } \\
\text { R Square }\end{array}$} & \multirow[b]{2}{*}{$\begin{array}{l}\text { Std. Error of } \\
\text { the Estimate }\end{array}$} & \multicolumn{5}{|c|}{ Change Statistics } \\
\hline & & & & & $\begin{array}{l}\text { R Square } \\
\text { Change }\end{array}$ & F Change & df1 & $\mathrm{df} 2$ & $\begin{array}{c}\text { Sig. F } \\
\text { Change }\end{array}$ \\
\hline 1 & $.941^{\mathrm{a}}$ & .885 & .881 & .062 & .885 & 185.219 & 8 & 192 & .000 \\
\hline
\end{tabular}

a. Predictors: (Constant), Representativeness bias, Gambler_Overconfidence_bias, Mental_Accounting_bias, Regret_Aversion_bias,

Herding bias, Availability bias, Anchoring bias, Loss_Aversion_bias

Dependent Variable: individual investor decision

Source: Research Output

The model summary presented in Table 11 , shows that the coefficient of determination R2 equals 0.885 . This means that; anchoring bias, availability bias, gambler's fallacy, overconfidence biases, herding bias, loss aversion bias, mental accounting bias, regret aversion bias and representativeness bias explain $88.5 \%$ of observed change in individual investor decision on the ZSE.

\subsubsection{Correlation Coefficients}

Table 12. Correlation coefficients

\begin{tabular}{|c|c|c|c|c|c|c|c|c|c|}
\hline & 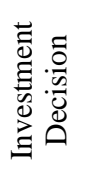 & 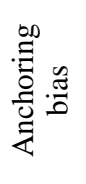 & 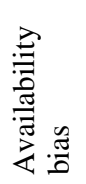 & 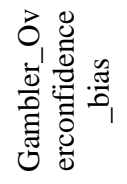 & 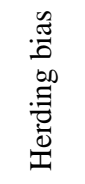 & 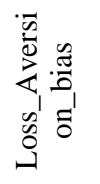 & 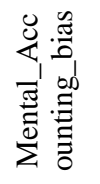 & 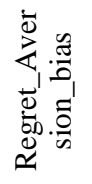 & 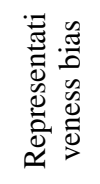 \\
\hline Investment Decision & 1 & & & & & & & & \\
\hline Anchoring bias & $.602^{* * 4}$ & 1 & & & & & & & \\
\hline Availability bias & $.489^{* *}$ & $.191^{* *}$ & 1 & & & & & & \\
\hline Gambler_Overconfidence_bias & $.489^{* * 4}$ & $.173^{*}$ & $.176^{*}$ & 1 & & & & & \\
\hline Herding bias & 0.089 & 0.102 & -0.07 & $-.147^{\prime \prime}$ & 1 & & & & \\
\hline Loss_Aversion_bias & $.539^{* * 4}$ & $.213^{* *}$ & $296^{* *}$ & $.318^{* * 1}$ & -0.1 & 1 & & & \\
\hline Mental_Accounting_bias & $.145^{*}$ & 0.013 & -0.13 & -0.06 & -0.11 & -0.03 & 1 & & \\
\hline Regret_Aversion_bias & $.422^{* *}$ & $.258^{* *}$ & -0.07 & 0.019 & $.180^{*}$ & -0.02 & 0.125 & 1 & \\
\hline Representativeness bias & $.291^{* *}$ & 0.05 & $.200^{* * 4}$ & 0.005 & 0.018 & 0.105 & 0.005 & -0.11 & \\
\hline
\end{tabular}

**. Correlation is significant at the 0.01 level (2-tailed).

*. Correlation is significant at the 0.05 level (2-tailed).

Source: Research Output 
Table 12 shows the correlation coefficient matrix of the predictor variables. The findings of the study established that the predictor variables were shown to have a strong positive association between them and individual investor decision at a significant level of 0.01 and 0.005 and hence included in the analysis.

\subsubsection{Analysis of variance (ANOVA)}

The researcher sought to compare means using analysis of variance.

Table 13. Analysis of Variance (ANOVA)

\begin{tabular}{|ll|r|r|r|r|r|}
\hline Model & \multicolumn{2}{|c|}{ Sum of Squares } & Df & Mean Square & F & Sig. \\
\hline 1 & Regression & 5.722 & 8 & .715 & 185.219 & $.000^{\mathrm{a}}$ \\
\hline & Residual & .741 & 192 & .004 & & \\
\hline & Total & 6.464 & 200 & & & \\
\hline
\end{tabular}

a. Predictors: (Constant), Representativeness bias, Gambler_Overconfidence_bias, Mental_Accounting_bias, Regret_Aversion_bias, Herding bias, Availability bias, Anchoring bias, Loss_Aversion_bias

b. Dependent Variable: individual investor decision

Source: Research Output

The significant value of the ANOVA test is 0.000 which is less than 0.05 . This shows that the independent variables are statistically significant in predicting investment decisions.

\subsubsection{Regression coefficients}

Table 14 shows the results of the regression coefficients required to form the multiple regression models.

Table 14. Regression coefficients

\begin{tabular}{|c|c|c|c|c|c|}
\hline \multirow[b]{2}{*}{ Model } & \multicolumn{2}{|c|}{ Unstandardised Coefficients } & \multirow{2}{*}{$\begin{array}{l}\begin{array}{l}\text { Standardised } \\
\text { Coefficients }\end{array} \\
\text { Beta }\end{array}$} & \multirow[b]{2}{*}{$\mathrm{t}$} & \multirow[b]{2}{*}{ Sig. } \\
\hline & $\mathrm{B}$ & Std. Error & & & \\
\hline 1 (Constant) & .392 & .120 & & 3.272 & .001 \\
\hline Anchoring bias & .117 & .010 & .319 & 11.994 & .000 \\
\hline Availability bias & .114 & .010 & .300 & 11.235 & .000 \\
\hline Gambler_Overconfidence_bias & .199 & .017 & .310 & 11.765 & .000 \\
\hline Herding bias & .062 & .015 & .103 & 4.019 & .000 \\
\hline Loss_Aversion_bias & .139 & .013 & .280 & 10.362 & .000 \\
\hline Mental_Accounting_bias & .073 & .011 & .172 & 6.836 & .000 \\
\hline Regret_Aversion_bias & .123 & .009 & .345 & 13.159 & .000 \\
\hline Representativeness bias & .075 & .009 & .221 & 8.750 & .000 \\
\hline
\end{tabular}

Source: Research Output

From the regression results in Table 14, the multiple linear regression model is;

$\mathrm{Y}=\beta 0+\beta 1 \mathrm{X} 1+\beta 2 \mathrm{X} 2+\beta 3 \mathrm{X} 3+\beta 4 \mathrm{X} 4+\beta 5 \mathrm{X} 5+\beta 6 \mathrm{X} 6+\beta 7 \mathrm{X} 7+\beta 8 \mathrm{X} 8$

This becomes;

$\mathrm{Y}=0.392+0.117 \mathrm{X} 1+0.114 \mathrm{X} 2+0.199 \mathrm{X} 3+0.062 \mathrm{X} 4+0.139 \mathrm{X} 5+0.073 \mathrm{X} 6+0.123 \mathrm{X} 7+0.075 \mathrm{X} 8$

The multiple linear regression model indicates that all the independent variables have a positive coefficient. According to the regression equation above, the amount invested will be at 0.392 units assuming all the behavioural factors are held constant at zero. The standardised beta coefficients give a measure of the contribution of each variable to the model. A large value indicates that a unit change in the predictor variable has a large effect on the criterion variable. The regression results above indicate that there is a positive relationship between dependent variable (individual investor decision) and independent variables, anchoring bias, availability bias, gambler's fallacy and overconfidence biases, herding bias, loss aversion bias, mental accounting bias, regret aversion bias and representativeness bias).

\subsubsection{Factors that Impact on Individual Investor Decision-Making on the ZSE}

Eight biases were identified as having influence on the investors' decision-making. These are anchoring, availability, gambler's fallacy and overconfidence, herding, loss aversion, mental accounting, regret aversion and representativeness. From the study loss aversion bias (mean, 4.14 on a Likert scale of 1-5), regret aversion bias (mean, 4.13) and herding bias (mean, 4.08) were found to have the most influencing impact on individual investor decision-making on the ZSE. Regret aversion and loss aversion biases have significantly high impact on the individual investors of the ZSE as many 
researchers have noted that investors believe that this is a common behaviour consistent with decision-making on the stock markets. After a gain, investors usually seek more opportunities to invest and the prospects of making more gains. This, however, means they may make rushed decisions leading to losses. On the other hand, when faced with losses, investors tend to be careful in their next decisions. The findings are consistent with the arguments posited by Sudhir (2012) and also supported by Pompian (2012). Thus, Albaity and Rahman (2012) also explain the positive effects of regret aversion as investors fearing feelings of regret become more conservative in their approach to portfolio selection and become more risk-averse (Albaity and Rahman, 2012). Pompian (2012) further illustrates that, faced with continued losses; the feeling of continued regret may spur investors to quickly sell off falling stock thereby limiting further financial loss. The findings of the study also revealed the high availability of herding behaviour amongst the individual investors of the ZSE. This finding is consistent with the findings by Kengatharan and Kengatharan (2014) and Wamae (2013) who found herding biases having a high impact on investor decision making. However, on the other hand the findings are not consistent with findings by Luong and Thu $\mathrm{Ha}$ (2011) who concluded that herding behaviour had no significant impact on investors' decision making and findings by Lim (2012) who documented that most investors thought it inappropriate to make decisions by simply following the mass.

Other behavioural biases were identified and have moderate impact on the investors' decision-making on the ZSE. These include; representativeness (3.96), availability (3.94), mental accounting (3.89), anchoring (3.86) and gambler's fallacy and overconfidence (3.83). As in the literature review section, the identified behavioural biases exist on the ZSE and have an impact on their decision-making. The findings further support the emerging branch of finance, behavioural finance, by showing evidence that individual investors do not always act rationally when making investment decisions but are affected by psychological biases as evidenced by the identified behavioural biases and impact levels.

The reliance by individual investors on the ZSE to use the purchase price of a stock to benchmark it against the future price shows that investors were not guided by rationality but rather anchoring bias. This explains the common phenomenon whereby investors continually hold onto losing stock. The findings of the study are similar to Luong and Thu Ha (2011), in their study on the Vietnam Stock Exchange in which they found that anchoring bias had a moderate impact (mean, 3.44).

The study findings showed that individual investors of the ZSE believe that all the successes of their investments can be attributed to their experience and knowledge of the market, thus they tend to highly rely on their own competences. This finding is consistent with the findings of the study conducted by Bakar and Yi (2016) and Lim (2012). However, a study by Kengatharan and Kengatharan (2014) showed that overconfidence had a negative relation with investment decision. Luong and Thu Ha (2011), in their study indicated that gambler's fallacy had a low impact on decision-making. This is different from the findings of this study which shows a moderately high impact level. For ZSE this relatively high impact level resonates well with the overconfident nature of the individual investors. Several studies have shown that gambler's fallacy is a prominent factor influencing investment decisions by individual investors. In the study of the investors on the Bombay Stock Exchange, Rakesh (2014) found that there existed evidence of gambler's fallacy in expectations of investors thereby affecting the quality of decisions adversely.

From the study, individual investors on the ZSE rely mostly on easily available information for making decisions. The findings concur with the findings of the study by Luong and Thu Ha (2011) who found availability bias to have moderate impact level on investor decision-making. The findings of the research by Luong and Thu Ha (2011) affirmed that mental accounting bias had a high impact level. This is similar to the current study's findings which confirm that individual investors at the ZSE tend to separate their investment portfolios and completely ignore the relationship between investment portfolio diversification.

\section{Conclusion and Recommendations}

\subsection{Conclusion}

To succeed in investment, one has to be efficient in selecting securities to include in their portfolio. However, efficiency alone does not guarantee consistent profits; it is also how one goes about in making investment decisions in the dynamic and ever-changing stock markets. Rational decision-making behaviour is crucial in sustaining investments on the stock market. However, in practice the concept of rational behaviour is rarely given second thought, decision making is affected by psychological fundamentals that go against the basic tenets of traditional financial models. Several studies have been conducted in other countries to try and lift the veil on the psychological biases that impact on individual investors' decision making. However, at the ZSE no such study had been conducted. The study sought to explore the behavioural factors at the core of investment decision making by individual investors on the ZSE.

The study identified eight factors which influenced individual investment decisions. These include anchoring, availability, gambler's fallacy, overconfidence, herding, loss aversion, mental accounting, regret aversion and representativeness. Regarding the impact levels of the factors, the findings showed certain biases overwhelm investors resulting in them 
being irrational in their investment decisions. The most prevalent behavioural factors were herding, regret aversion and loss aversion biases. The remaining biases all had relatively moderate impact on the individual investors' decision making. Correlation and regression models established a positive relationship between the behavioural factors and the individual investment decision.

\subsection{Recommendations}

Firstly, the study recommends that individual investors should avoid mental accounting bias as this is not best investment practice. But rather, an investment portfolio should be viewed as a combination of all the underlying individual stocks. That way, the upturn and downturns in individual stocks will have the effect of compensating each other and provide an overall good return on the investment.

Secondly, stockbrokers and other capital market players should endeavour to come up with tailor-made marketing and products for individual investors. The emphasis is on removing the complexities associated with the technical jargon of the stock market world. Brochures should be simplified as much as possible for ease of understanding by the individual investors.

Furthermore, SECZ should also advocate for more investor training courses which can start from beginner up to expert level depending on the investors' level of financial literacy and trading experience.

Finally, the capital market players should also lobby for the reduction of transaction costs which remain high compared to other regional bourses. This will allow more individual investors to participate on the stock exchange and in turn increase activity and liquidity.

\section{References}

Agarwal, A. K., \& Panwar, V. (2014). Impact of Behavioural Finance Theories on Individual Investor's Decision-Making. International Journal of Management Research and Development, 2(2), 89-96.

Ahmad, Z., Ibrahim, H., \& Tuyon, J. (2017). Institutional investor behavioral biases: syntheses of theory and evidence. Management Research Review, 40(5), 578-603. https://doi.org/10.1108/MRR-04-2016-0091

Albaity, M. S., \& Rahman, M. (2012). Gender, ethnicity, and religion and investment decisions: Malaysian evidence. Journal of Sociological Research, 3(2), 502-519. https://doi.org/10.5296/jsr.v3i2.2649

Bakar, S., \& Yi, A. (2016). The Impact of Psychological Factors on Investors' Decision Making in Malaysian Stock Market: A Case of Klang Valley and Pahang. Procedia Economics and Finance, 35, 319-328. https://doi.org/10.1016/S2212-5671(16)00040-X

Barron, G., \& Leider, S. (2010). The role of experience in the gambler's fallacy. Journal of Behavioural Decision-Making, 23, 117-129. https://doi.org/10.1002/bdm.676

Beck, A. T., Rector, N. A., Stolar, N., \& Grant, P. (2008). Schizophrenia: Cognitive theory, research, and therapy. Guilford Press.

Chang, C. (2008). The impact of behavioural pitfalls on investors' decisions: the disposition effect in the Taiwanese Warrant Market. Social Behaviour and Personality, 36(5), 617-634. https://doi.org/10.2224/sbp.2008.36.5.617

Chengetedzai.co.zw. (2019). Chengetedzai Depository Company | ABOUT US. [Online]. Retrieved May 27, 2019, from http://www.chengetedzai.co.zw/about-us-2/

Escrow Systems (2019). Frequently Asked Questions | C-Trade. [Online] Retrieved April 30, 2019 from https://ctrade.co.zw/faqs/

Faff, R., Hallahan, T., \& McKenzie, M. (2009). Nonlinear linkages between financial risk tolerance and demographic characteristics. Applied Economics Letters, 16(13), 1329-1332. https://doi.org/10.1080/13504850701381123

Fama, E. F. (1970). Efficient Capital Markets: A Review of Theory and Empirical Work. Journal of Finance, 25(2), 383-417. https://doi.org/10.2307/2325486

Goldstein, E. B. (2013). Cognitive Psychology: Connecting Mind, Research and Everyday Experience. USA: Wadsworth Publishing.

Gunay, S. G., \& Demirel, E. (2011). Interaction between Demographic and Financial Behaviour Factors in Terms of Investment Decision-making. International Research Journal of Finance and Economics, 66(2), 147-156.

Inaishi, R., Toya, K., Zhai, F., \& Kita, E. (2010). Effect of Overconfident Investor Behaviour to Stock Market. Journal of Advanced Computational Intelligence and Intelligent Information 14(6), 661-668.

https://doi.org/10.20965/jaciii.2010.p0661 
Jain, D., \& Mandot, N. (2012). Impact of Demographic Factors on Investment Decision of Investors in Rajasthan. Journal of Arts, Science and Commerce, 3(2), 81-92.

Jamshid, D. B., Chavoshani, C., \& Amiri, S. (2012). The Impact of Demographic and Psychological Characteristics on the Investment Prejudices in Tehran Stock. European Journal of Business and Social Sciences. 1(5), 41-53.

Jureviciene, D., \& Kristina, J. (2012). The Impact of Individuals' Financial Behaviour on Investment Decisions. Paper presented at the annual meeting for the Society of 1st. Electronic International Interdisciplinary Conference, Slovakia, September 3-7.

Kahneman, D., \& A. Tversky. (1979). Prospect Theory: An Analysis of Decision under Risk. Econometrica, 47(2), 263-291. https://doi.org/10.2307/1914185

Kahneman, D., Knetsch, J. L., \& Thaler, R. H. (1991). Anomalies: The endowment effect, loss aversion, and status quo bias. Journal of Economic perspectives, 5(1), 193-206. https://doi.org/10.1257/jep.5.1.193

Kaleem, A., Wajid, R. A., \& Hussain, H. S. (2009). Factors Affecting Financial Advisor's Perception in Portfolio Management: With Reference to Pakistan. Oxford Business and Economics Conference Program, June: 24-26.

Kartasova, J. (2013). Factors forming irrational Lithuanian individual investors' behaviour. Verslo Sistemos ir Ekonomika, $3(1), 69-78$.

Kengatharan, L., \& Kengatharan, N. (2014). The influence of behavioural factors in making investment decisions and performance: Study on investors of Colombo Stock Exchange, Sri Lanka. Asian Journal of Finance and Accounting, 6(1), 1-23. https://doi.org/10.5296/ajfa.v6i1.4893

Kudryavtsev, A., \& Cohen, G. (2011). Behavioural Biases in Economic and Financial Knowledge: Are They the Same for Men and Women? Advances in Management and Applied Economics, 1(1), 15-52.

Laibson, D., \& Zeckhauser, R. (1998). Amos Tversky and the Ascent of Behavioural Economics. Journal of Risk and Uncertainty, 16, 7-47. https://doi.org/10.1023/A:1007717224343

Lakshmi, P., Visalakishmi, S., Thamaiselvan, N., \& Senthilarasu, B. (2013). Assessing the Linkage of Behavioural Traits and Investment Decisions using SEM Approach. Journal of Economics and Management, 10(3), 306-315.

Levine, R. (1997). Financial Development and Economic Growth: Views and Agenda. Journal of Economic Literature, 35(2), 688-726.

Lin, H. (2011). Elucidating the Influence of Demographics and Psychological Traits on Investment Biases. World Academy of Science, Engineering and Technolog, 5(5), 137-142.

Lin, H. (2012). How Herding Bias Could Be Derived From Individual Investor Types and Risk Tolerance? World Academy of Science, Engineering and Technology, 6(6), 767-772.

Luong, L. P., \& Thu Ha, D. T. (2011). Behavioural Factors Influencing Individual Investors' Decision-Making and Performance: A survey at the Ho Chi Minh Stock Exchange, Master thesis, Umeå School of Business, Umeå University, Vietnam.

Mugenda, O. M., \& Mugenda, A. G. (2003). Research methods: Quantitative \& qualitative approaches. Nairobi: African Centre for Technology Studies.

Murgea, A. (2010). Classical and Behavioural Finance in Investor Decision. Annals of University of Craiova-Economic Sciences Serie, 2(38), 212-223.

Pompian, M. M. (2012). Behavioural finance and investor types: Managing behaviour to make better investment decisions. Hoboken, N.J: Wiley. https://doi.org/10.1002/9781119202417

Rakesh, H. M. (2014). A study on individual investors' behaviour in stock markets of India. International Journal in Management \& Social Science, 2(2), 165-174.

Ricciardi, V. (2004). A risk perception primer: A narrative research review of the risk perception literature in behavioural accounting and behavioural finance. Working paper. https://doi.org/10.2139/ssrn.566802

Ritter, J. R. (2003). Behavioural Finance Pacific-Basin. Finance Journal, 11(4), 429-437. https://doi.org/10.1016/S0927-538X(03)00048-9

Seczim.co.zw. (2019). Who is SECZ - Securities and Exchange Commission of Zimbabwe (SECZ). [Online]. Retrieved May 27, 2019 from http://www.seczim.co.zw/about-secz/who-is-secz

Sewell, M. (2011). History of the efficient market hypothesis. Research Note, 11(04), 04. 
Sharpe, W. F. (1964). Capital asset prices: A theory of market equilibrium under conditions of risk. The Journal of Finance, 19(3), 425-442. https://doi.org/10.1111/j.1540-6261.1964.tb02865.x

Shiller, R. J. (2002). From Efficient Market theory to Behavioural Finance. Cowles Foundation Discussion papers No. 1385. New Haven: Yale University.

Shiller, R. J. (2015). Irrational exuberance. Princeton University Press, Chicago. https://doi.org/10.1515/9781400865536

Singh, S. (2012). Investor irrationality and self-defeating behaviour: Insights from behavioural finance. The Journal of Global Business Management, 8(1), 116-122.

Subash, R. (2012). Role of Behavioral Finance in Portfolio Investment Decisions: evidence from India, Charles University in Prague Faculty of Social Sciences Institute of Economic Studies, Master Thesis.

Thaler, R. (2001). Theory of mental accounting. New York: Academic Press.

Tripathy, C. K. (2014). Role of Psychological Biases in the Cognitive Decision Making Process of Individual Investors. Orissa Journal of Commerce, 34(1), 69-80.

Tversky, A. (1995). The Psychology of Decision-making, in Wood, Arnold S. (ed.), Behavioural Finance and Decision Theory in Investment Management, Virginia, USA: Association for Investment Management and Research. https://doi.org/10.2469/cp.v1995.n7.1

Wamae, J. N. (2013). Behavioural factors influencing investment decision in stock market: A survey of investment banks in Kenya. International Journal of Social Sciences and Entrepreneurship, 1(6), 68-83.

\section{Copyrights}

Copyright for this article is retained by the author(s), with first publication rights granted to the journal.

This is an open-access article distributed under the terms and conditions of the Creative Commons Attribution license which permits unrestricted use, distribution, and reproduction in any medium, provided the original work is properly cited. 